\title{
The Translation and Dissemination of $\mathrm{Chu} C \mathrm{C}$ in Europe
}

\author{
Nan Chen, Chuanmao Tian
}

\author{
School of Foreign Studies, Yangtze University, Hubei, 434023 PRC China
}

\begin{abstract}
This paper combs through the translation and dissemination forms of Chu Ci in Europe from the perspective of time. Before the twentieth century is the early stage and its major dissemination form develops from reference translation to systemic one. Representative works of this stage includes the translation of Pfizmaier and Denys. The modern stage is divided by the first half of the twentieth century and Chu Ci began to treated as an subject in European Universities. Research perspectives on Chu Ci started to expand. From the later half of twentieth century to the presentis the contemporary stage.Complete translation versions of Chu Ci had appeared. Eastern Europe emerged as a new force in the translation of Chu Ci. At the end, major translation achievements and research angles will be summarized.
\end{abstract}

Keywords-Chu Ci; translation; Europe; Sinology.

\section{INTRODUCTION}

Unlike The Book of Songs and The Analects of Confucius, which are Chinese famous classic literature, the translation and dissemination of $\mathrm{Chu} C i$ are less concentrated in Europe(Guo 2013; Wei 2014; Yan 2013; Guo \& Cao 2014). Early work in the translation study of $\mathrm{Chu} C i$ tended to focus on the English world, ignoring the splendid contributions European sinologists had made(Chen 2013). In fact, it was initially introduced by Austrian sinologist August Pfizmaier in 1852 and it is found that European scholars have studied $\mathrm{Chu} \mathrm{Ci}$ for more than four hundred years. Under the backdrop of "Going global" strategy for Chinese culture development, it is of great significance to reflect on the translation and dissemination history of $\mathrm{Chu} C \mathrm{Ci}$ in Europe, which may lend perspective or paradigms for domestic academic circles and promote academic exchanges as well as the translation of Chinese classics.

Based on the translation history of $\mathrm{Chu} C i$ in Europe, it can be roughly divided into three main phases: the early study phase before the twentieth century, the modern study in the first half of the twentieth century, the contemporary study from the second half of the twentieth century to the present(He 2010; Chen 2013). In this study, it will introduce representative works of each phase and the developing characters in different stages, various dissemination forms ISSN: 2456-7620

https://dx.doi.org/10.22161/ijels.55.8 of $C h u C i$ in Europe will also be involved.

\section{THE EARLY STAGE:FROM REFERENCE} TRANSLATION TO SYSTEMIC TRANSLATION When it comes to the origin of the translation and dissemination in Europe, there are always different voices. Most of the relevant studies believed that it was German scholar August Pfizmaier that had first translated the poems of Chu Ci to the European and American world(He 2010; Wei 2014). He published Li Sao and Nine Songs in the Vienna Royal Academy of Sciences Report in 1852(He 2010). However, the latest research found that Portuguese Jesuit Emmanuel Dias Jr had already published"Tian Wen Lue"("The Summary of Tian Wen") in Beijing in 1615(Saraiva \& Jami 2008:185). Not only had the title created connection with Tian Wen, but the content had included Emmanuel's answers to Qu Yuan's doubts. This can prove that the dissemination of $\mathrm{Chu} \mathrm{Ci}$ in Europe should trace back to 1615(Chen 2013). In fact, Emmanuel's work was used to preach under the cover of Chinese classics, which followed the "Spreading a religion through knowledge"strategy of Matteo Ricci. Whether Emmanuel could truly understand Chu Ci still remains some doubts. In 1728, French Jesuit Joseph de Prémare finished his book The Notitia Linguae Sinicae, in which he extolled the

https:/dx.doi.org/10.22161/ijels.55.8 
gorgeous metaphors in $\mathrm{Chu} \mathrm{Ci}$ and translated some of the verses(Mungello 1976). Joseph's book had lay a foundation for teaching Chinese, which made it possible for promoting Chinese culture in Europe(Demiéville \& Qin 1993).

In 1869,Marquis d'Hervey de Saint Denys, the French sinologist, completed his translation of Chu Ci Zhang Ju in French version which was published by Maisonneuve et cie, Nevertheless, this translation had not exerted much influence in the society and only enjoyed certain popularity in aristocratic salons(Xu 2013).

It was not until 1879 that $\mathrm{Chu} \mathrm{Ci}$ began to be translated into English, which should give the credit to Edward Harper Parker, the British ambassador to China(Guo \& Cao 2014). Ever since Parker had published his translation in China Review, the criticism came one after another for its Victorian poetry rhyme and a lack of deliberation. Herbert Allen Giles even thought that “...Parker, always too hasty a translator, followed up with serious mistakes.”(Lim Boon Keng 1974: xxi). Besides, David Hawkes (1962) described "It is reallly more a paraphrase than a translation." Since the unique feature of Chu $\mathrm{Ci}$ hadn't been fully displayed, it would be reasonable that most of western readers couldn't grasp the thought and emotions of the original text. But, his pioneering contribution of introducing $\mathrm{Chu} \mathrm{Ci}$ to English world cannot be ignored.

Herbert Allen Giles(1884:33-36), who was mentioned before, published his Gems of Chinese Literature in Shanghai which included the translation of "Yu Fu"("The Fisherman") and "Shan Gui"("The Mountain Spirit"), etc. Inspired by "Shan Gui", the poet Granmer Byne recreated it and put into his poetry anthology as The Land of Exile. Two years later, French poet Emile Blémont published Poèmes de Chine which incorporated different genres of Chinese classic literature such as Tang Poetry, Book of Songs and Li Sao(Ruan 2007). Rather than literal translation, their works were more like creative translation with multiple alterations in meaning, let alone the fallacies they had made. However, this kind of translation was highly accepted by the French, which had been quite conducive to the dissemination of $\mathrm{Chu}$ Ci.

French ambassador Edouard Chavanne came to China in 1889. He was the student of Marquis d'Hervey de Saint Denys and more renowned for his translation of The Records of History(B. Laufer 1918). Less understood was ISSN: 2456-7620 his indirect contribution to the interpretation of $\mathrm{Chu} \mathrm{Ci}$ through copious quotation while translating The Records of History. After that, he had also finished the translation of Tian Wen.

In 1892 and 1893, Belgian orientalist Charles Joseph de Harlez published La Poésie chinoise (Chinese Poetry), which translated part of Li Sao, Da Zhao, Nine Songs, and Tian Wen. It can be seen that there is great extension in the choice of $\mathrm{Chu} \mathrm{Ci}$ works, and his version is succinct and fluent(Chen 2013).

Different from other countries in Europe, Sinologists in Sweden and Dutch tended to focus on the geography and language rather than pure interpretation of Chinese literature(Idema 2014:7). J. J. M. de Groot is one of the examples and he had already published a useful study on the annual feasts and customs of the Amoy Chinese in 1880(Léonard Blussé, Harriet Thelma Zurndorfer \& Erik Jan Zürcher, 1993:286). Based on extensive field research and the analysis, the study compared Chinese Dragon Boat Festival with Europe ritual activities and draw a conclusion that the origin of Dragon Boat Festival was intended to sacrifice the Dragon instead of honouring Qu Yuan.

Similarly, Sweden sinologist Berhard Karlgren was expert in textual research and discerning the false from the genuine. He classified pre-Qin literature into two main categories: systematic and non-systematic and Li Sao belonged to the second one(Pee 2012). Some of those had been translated, but those translations aimed at philological correctness rather than literary elegance (Malmqvist 2016). That would explain why he was more renowned for his philological contribution to sinology.

\section{THE MODERN STAGE:FROM UNIVERSITY EDUCATION TO ACADEMIC DEBATE}

Sinology was widely established in European universities in the early 20th century, which has closely connection with external aggression. The main propagators and disseminating approaches have expanded. In the last stage, missioners, ambassadors and part of the sinologists were the active force. As for the translation works, little had been showed in a systematic way. After western countries had successfully opened the gate of China, purely translation on the text level couldn't satisfy those scholars any more and they began to further explore the mystery of the oriental 
culture.

In 1895, the missioner and scholar James Legge published The Lî Sâo Poem and Its Author in The Journal of the Royal Asiatic Society of Great Britain and Ireland. He was commonly known for the translation of Four Books and Five Classics which were regarded as the standard version and important research materials(Chen \& Liu 2008). He didn't start to translate $\mathrm{Chu} \mathrm{Ci}$ until later in his life and those works remained in the rough. But still, his rigorous attitude towards study had imparted every word in his works with sound evidence. China Review even described that "Legge's translation is the milestone in the history of sinology"(Lehrich, C.I. 2005:82-84).

In 1902, German sinology Wilhelm Grube completed Gschichte der Chineseischen Literature (A History of Chinese Literature), in which he translated "Yu Fu"(Fisherman) and "Li Sao"(Li 2008:56). He separated sinology from orientalism and gave priority to the national characteristics of culture. The readers could have a better understanding of the Chinese culture. nother German scholar August Conrady had planned to conduct a research on Tian Wen before lecturing on it in Universität Leipzig in 1907. However, he died before it was finished. (Chen \& Xu 2014). Fortunately, he had nurtured many excellent sinologists such as Eduard Erkes and Franz Xaver Biallas.

In 1913, Eduard Erkes finished his doctoral thesis about Zhao Hun. In 1929, he published Da Zhao in Asia Major with annotation based on his understanding of oriental folklore. In 1940, he published The God of Death in Ancient China in Tough Pao(Finsterbusch 1958). Besides, he also dug into the research on Qu Yuan. Similarly, his fellow disciple Franz Xaver Biallasdid his doctorial thesis on Chu Ci. In 1928, he published Kû Yuân, his life and poems. No matter from the content or emotion, this article was displayed with strong character of European biographies written at the end of 19th century. In 1933, he worked as a teacher in $\mathrm{Fu}$ Jen University in Beijing and started a publication named Monumenta Serica. Over the next two years, Biallas gradually translated Nine Chapters in Germany.

For those contributions that Conrady and his students had made, previous scholars didn't stint their compliments. Zhen(2014) described “...these German scholars promoted the dissemination of Qu Yuan and his work in the west, as ISSN: 2456-7620 well as the understanding of the early Chinese traditional customs." Moreover, their thorough studies about $\mathrm{Chu} \mathrm{Ci}$ symbolized that $\mathrm{Chu} \mathrm{Ci}$ had became a special research direction in European universities.

Compared with other countries in the Europe, Britain is relatively late in the study of $\mathrm{Chu} \mathrm{Ci}$. But, it quickly caught up from the behind. Excellent research groups and comprehensive outcomes came forward in large numbers. Among the multiple outstanding scholars, two of them deserve to be introduced in details: Herbert A. Giles, who had been mentioned in the last part, and Arthur D. Waley. In 1916, Arthur Waley published Chinese Poems in London, including Nine Songs and $\mathrm{Li}$ Sao. Different from the previous scholars, Waley adopted Chu Ci Zhang Ju of Wang $\mathrm{Yi}$ as his annotation. Two years later, he further translated Guo Shang, combining with Li Sao and Nine Songs, A Hundred and Seventy Chinese Poems successfully came out(Guo \& Cao 2014). In 1919, this book went through countless edition and was welcomed in the Europe.

In 1927, Henri Maspero, the chair of Chinese at Collège de France, published his monumental La Chine Antique(Loewe 1980). He believed that the new poems created by Qu Yuan had subverted the Book of Songs both in terms of spiritual level and literature genre. Long poems began to be widely used in sentimental act.

Out of the interests towards the Catholics in China, Gaberiele Maria Allegra came to China and later became the chaplain. Apart from the missionary work, Allegra also put his energies on translating Li Sao into Italian, which was published in Shanghai in 1938(Raissa De Gruttola 2015).

In 1943, B.M. Anexcess, an academician of the Soviet Academy of Science, directed Federlin to obtain a doctorate by studying the life story of Qu Yuan. Professor E. A. Serebrjakov, another representative of the study of $\mathrm{Chu} \mathrm{Ci}$ during Soviet Union period, organized a long paper to detailedly analyze the works of Chu poets(Chen, 2007). The studies about $\mathrm{Chu} \mathrm{Ci}$ in Soviet period were obviously not broad enough when compared with other countries in Europe. Instead, Chinese classic novels and mythologies frequently appeared in their research.

As it shows from the above, one of the most obvious features in this period is that $\mathrm{Chu} \mathrm{Ci}$ began to be treated as a subject in European Universities, which encouraged the emergence of excellent sinologists like Eduard Erkes and 
Franz Xaver Biallas. History of Chinese Literature revised by Giles in 1901 marked that Cambridge became the first University to teach Chu Ci in England(Knechtges 2018). After the World War II, more and more doctoral dissertations was about $\mathrm{Chu} \mathrm{Ci}$. Moreover, academic contention also promoted the development of studies on Chu $\mathrm{Ci}$ to some extent. For example, the controversy about translation of Da Zhao between H. A. Giles and Arthur Waley. Giles criticized that Waley didn't remain true to the original in the pursuit of readability(Yang 2014). Even though Waley contradicted that it was possible to adopt proper literary translation especially for poems, we can see from Waley's later works that his translation strategies was keeping revised(He 2010). In this sense, it can be found that the contradictions between scholars hadalso made contributions to the translation of $\mathrm{Chu} \mathrm{Ci}$ and its related studies.

\section{THE CONTEMPORARY STAGE:FROM COMMEMORATION TO DIVERSIFIED RESEARCH}

During this period, politic played a vital role in the translation process of Chu $\mathrm{Ci}$. Especially the establishment of UNESCO which was dominated by European countries. For a series of complex politic reasons, Russia was pushed to the periphery: only four books were translated from Russian, and none were translated into Russian(Yifeng Sun \&Chris Song 2019:).That's why the government actively engaged with other countries through various cultural activities, which in turn helped to cultivate political alliances. Thanks to these, Chinese traditional literature came to the front and gained more attention in the eastern Europe.

Literary translation underwent an significant revival after Stalin's death in1953---the time when Akhmantova published her translation of Li Sao. Akhmantova didn't blindly pursue the rhyme and the rhythmic modes varied greatly even in the sentence that was supposed to be rhythmic. But she succeeded in expressing the main idea of Li Sao(Zhang 2011). In 1986, the famous sinologist Federlin integrated his years of researches into one book in which he gave us details about Qu Yuan and his great works(Xu 2013:29). Federlin put his focus not only on the translation of $\mathrm{Chu} \mathrm{Ci}$, but on the life experience as well as ISSN: 2456-7620 the writer's personalities.

Besides, Polish sinologist Janusz Chmielewki published the proceedings of conference to commemorate Qu Yuan in 1954(Wei 2011). The proceeding includes multiple works of outstanding scholars such as Aleksego Debnickiego and Olgierd Adrian Wojtasiewicz, etc (Rudakowska 2014).Four years later, Chmielewki translated the poems of Qu Yuan. Different from other translators, he referred to the creation of Chinese scholars in this area like Guo Moruo and Yang Hsien. It was obvious that cultural communication between countries was of great significance to disseminate Chu culture.

In 1953, Romanian Academy of Science held a memorial for Qu Yuan. In 1974, Ileana Hogea-Veliscu and Iv Martinovici jointly translated the poems of $\mathrm{Qu}$ Yuan, including Li Sao, Nine Songs, Nine Chapters and part of Tian Wen(Chen 2013). As we can see, the great cultural countries in Europe such as English and German tend to have a longer research history than eastern Europe. Moreover, sinological research in most European countries began to cover a wider range of subjects at this stage(Zhen 2014). Academics act as individual researchers, not as members of a certain "school." Research centers, specialized discussion lists and conferences further enhance the built up of international networks of scholars working in the same field.

Apart from the wider research angles, more and more translation of Chu $\mathrm{Ci}$ appeared in the form of full text. In 1955, Arther Waley published The Nine Songs, A Study of Shamanism in Ancient China(Guo 2013). At the same year, English scholars David Hawkes finished his doctoral thesis "The Problem of Date and Authorship in Chu Tzu" in Oxford University(Wei 2014). Later, this thesis was published as monograph in 1959. Based on the translations of these two excellent translators, German scholar Peter Weber translated Nine Songs, Tian Wen, Zhao Hun, Da Zhao and Li Sao in 1967. Rita Keindorf(1999) published her doctoral dissertation Mystische Reise im Chuci. One major feature of this thesis lied that it had elucidated the philosophy and literature meaning. In 1992 and 1999, Micheal Schimmelpfenning's master thesis and doctoral thesis were both concerned with $\mathrm{Chu} \mathrm{Ci}$. $\mathrm{He}$ was so interested in $\mathrm{Chu} \mathrm{Ci}$ that had already published dozens of research papers to discuss it from different angles by now 
(Schimmelpfennig, M 2004). The main idea he wanted to express in his articles was that Chu Ci Zhang Ju was the result of joint efforts rather than the glory of Wang Yi alone In addition, there are a lot of other materials about $\mathrm{Chu} \mathrm{Ci}$ in the anthology of ancient Chinese literary history, encyclopedias, newspapers and magazines which are compiled by European scholars, but the list gets too long to include here.

\section{CONCLUSION}

On the whole, the study of $\mathrm{Chu} \mathrm{Ci}$ in Europe starts with the translation of some chapters of $\mathrm{Chu} \mathrm{Ci}$ and gradually develops into a comprehensive study which may be interpreted from new research angles such as anthropology and religion. Throughout the history of translation development of $\mathrm{Chu} \mathrm{Ci}$, there are two aspects that deserves our attention:

In terms of translation, the full translations of $\mathrm{Chu} \mathrm{Ci}$ in English and French have appeared, which provides the authoritative reference for Western sinologists to further conduct research. To achieve a better effect of the dissemination of $\mathrm{Chu} \mathrm{Ci}$, Chinese scholars in related areas may work together to publish our own full translation in multiple languages. This may help the foreigners to truly understand the cream of Chinese classic literature. In terms of research, European scholars tend to study $\mathrm{Chu} \mathrm{Ci}$ from four main angles: firstly, the origin of $\mathrm{Chu}$ Culture; Secondly, the relation between Chu Ci and Taoism; Thirdly, the relation between $\mathrm{Chu} \mathrm{Ci}$ and Shaman Culture; Fourth, the language form of $\mathrm{Chu} \mathrm{Ci}$. As it shows that European sinologists tend to explore the culture connotation from the aspects such as religion and nationality, which is quite different from the Chinese scholars.

There is no denying that those translations exist in some problems due to the different cultural background, but it is their relentless effort that has aroused the scholars' comments and therefore promote the sudy of $\mathrm{Chu} \mathrm{Ci}$ in Europe. In order to truly expand the influence of Chu culture and even Chinese culture overseas, it's necessary to conduct a comprehensive induction of its translation and related research, which is also the key for taking Chinese classic culture to the global stage.

\section{REFERENCES}

[1] Anna Rudakowska (2014). The Study of China in Poland ISSN: 2456-7620 after World War II: Toward the "New Sinology", China Review, 14, 59-90.

[2] B. Laufer (1918). Édouard Chavannes. Journal of the American Oriental Society, 38, 202-205..

[3] Charles de Harlez, "La Poésie chinoise", Bulletins del'A-cadémie royale de Belgique, 24, 1892: 161-209; 25, 1893:148-156.

[4] Chen, Liang. (2013). A Summary of Chu Ci Studies in Europe.Jiangsu Social Sciences, 6, 191-196.

[5] Chen Kepei, Liu Hongxin (2008). A Survey of the Study of James Legge. Translation of Shanghai. 2, 18-22.

[6] David E. Mungello. (1976). The Reconciliation of Neo-Confucianism with Christianity in the Writings of Joseph de Prémare, S. J. Philosophy East and West, 26, 389-410.

[7] David Hawkes. (1962). Ch'u Tz'u: the Songs of the South, an Ancient Chinese Anthology, Boston: Beacon Press.

[8] David R. Knechtges (2018). The Multilingual Dimensions of International Sinology. Tsi Hua Journal of Chinese Studies, 20, 9-45.

[9] Field Stephen (1986). Tian Wen: A Chinese Book of Origin. New York: A New Directions Book.

[10] Göran Malmqvist (2016). Berhard Karlgren: the man behind the scholar. Springer Berlin Heidelberg, 3(3): 513-521.

[11] Girardot, Norman J (2002). The Victorian Translation of China: James Legge's Oriental Pilgrimage. Berkeley: University of California Press, USA.

[12] Guo Xiaochun, Cao Shunqing (2014). The Communication and Acceptance of Chu ci in the English World. Seeking Truth. 2. 128-134.

[13] H. A.Giles. (1884). Gemsof Chinese Literature, Shanghai: Kelly and Walash.

[14] H. A. Giles (1901). A History of Chinese Literature, New York: Appleton and Company.

[15] He Wenjing. (2010). Translation and Spreading of Chu Ci Culture in the West. Three Gorges Forum, 5, 42-49.

[16] Käte Finsterbusch (1958). In Memoriam: Eduard Erkes 23. Juli 1891-2. Artibus Asiae, 21(02): 166-170.

[17] Keindorf, R. (1999). Die mystische Reise im Chuci: Qu Yuans (ca. 340-278 v. Chr.) Yuanyou vor dem Hintergrund der zeitgenössischen Philosophie und Dichtung. Shaker.

[18] Léonard Blussé, Harriet Thelma Zurndorfer \& Erik Jan Zürcher (1993). Conflict and Accommodation in Early Modern East Asia: Essays in Honour of Erik Zürcher, BRILL. 
[19] Legge (1895). The Lî Sâo Poem and Its Author. The Journal of the Royal Asiatic Society of Great Britain andIreland, 839-864.

[20] Luis Saraiva, Catherine Jami. (2008). The Jesuits, the Padroado and East Asian Science(1552-1773). World Scientific Publishing Co. Pte. Ltd.

[21] Lim Boon Keng (1974). The Li Sao An Elegy on Encountering Sorrows by Chu Yuan, The Commercial Press Limited.

[22] Michael Loewe (1980). China in Antiquity. By Henri Maspero, translated by Frank A. Kierman Jr. William Dawson and Son Ltd, Folkstone, xxxii,527.

[23] Paul Demiéville \& Qin Shiyue. (1993). An Overview of the History of Sinology in France. Chinese Culture Research, 2, 131-139.

[24] Raissa De Gruttola (2015). The First Catholic Bible in Chinese: Gabriele Allegra and His Translation, International Journal of Area Studies, 10, 1, 5-23.

[25] Schimmelpfennig, M. (2004). The Quest for a Classic: Wang Yi and the Exegetical Prehistory of his Commentary to the Songs of Chu. Early China, 29, 111-162

[26] Wilhem Grube (1902). Geschichte der Chineschen Litteratur. Leipzig: C.F. Amelang.

[27] Wilt Idema (2014). Chinese Studies in the Netherlands: Past, Present and Future. Brill.

[28] Xu Zhixiao (2013). Chinese Ancient Literature in Europe. Hebei Publishing Media Press.

[29] Yifeng Sun, Chris Song (2019). Translating Chinese Art and Modern Literature. London: Routledge.

[30] Zhang Shujuan (2011). The Spread of Chu Ci(Songs of Chu) in Russia, Russian Literature \& Arts, 4, 105-108.

[31] Chen Liang, Xu Meide (2014). A Study of the German Sinologist August Conrady's Tianwen, Reasearch on Chinese Literature, 2:126.

[32] Chen Youbing (2007). The Research Process and Academic Features of Chinese Classical Literature in Soviet Russia, Yangtze River Academic, 2, 31-41.

[33] Guo Xiaochun (2013). A Review of the Translation and Research of Chu Ci in the English World, Cultural Studies and Literary Theory, 24, 44-57.

[34] Li Xuetao (2008). Sinology in Germanic Academic Pedigree-A study of Sinology in Germany, Foreign Language Teaching and Research Press.

[35] Ruan Jieqing (2007). Histoire de l'introduction de la poésie ISSN: 2456-7620 classique chinoise en France, Etudes Francaises, 1, 1-8.

[36] Wei Jiahai (2014). The English Translation of Chu Ci and Its Research Review, Minority Translators Journal, 1, 89-96.

[37] Zbigniew Wesolowski SVD (2011). Polish Sinological Studies: The Past and Present, Chinese Studies, 13, 53-96.

[38] Yang Liu (2014). The Cambridge Tradition in Sinological and Translation Studies Since the $19^{\text {th }}$ Century, Chinese Translators Journal, 4, 26-31.

[39] Zhen Youjie (2014). A Review of Overseas Studies of Chu Ci, Study and Practice, 4, 135-140. 